\title{
Reduced Laterality as a Trait Marker of Schizophrenia-Evidence from Structural and Functional Neuroimaging
}

\author{
Viola Oertel, ${ }^{1,2}$ Christian Knöchel, ${ }^{1}$ Anna Rotarska-Jagiela, ${ }^{3,5}$ Ralf Schönmeyer, ${ }^{1}$ Michael Lindner, ${ }^{1,2}$ \\ Vincent van de Ven, ${ }^{4}$ Corinna Haenschel, ${ }^{1,5,6}$ Peter Uhlhaas, ${ }^{1,5}$ Konrad Maurer, ${ }^{1}$ and David E. J. Linden ${ }^{1,6}$ \\ ${ }^{1}$ Neurophysiology and Neuroimaging Laboratory, Department of Psychiatry, and ${ }^{2}$ Brain Imaging Centre, Goethe University, 60528 Frankfurt/Main, \\ Germany, ${ }^{3}$ Department of Psychiatry, University of Cologne, 50923 Cologne, Germany, ${ }^{4}$ Department of Neurocognition, University of Maastricht, 6200 MD \\ Maastricht, The Netherlands, ${ }^{5}$ Max Planck Institute for Brain Research, 60528 Frankfurt am Main, Germany, and ${ }^{6}$ School of Psychology, Bangor University, \\ Bangor LL57 2AS, United Kingdom
}

Laterality is a characteristic principle of the organization of the brain systems for language, and reduced hemispheric asymmetry has been considered a risk factor for schizophrenia. Here we sought support for the risk factor hypothesis by investigating whether reduced asymmetry of temporal lobe structure and function is also present in unaffected relatives. Sixteen schizophrenia patients, 16 age-matched first-degree relatives, and 15 healthy controls underwent high-resolution three-dimensional anatomical imaging and functional magnetic resonance imaging during auditory stimulation. Both the overall auditory cortex and planum temporale volumes and the lateralization to the left hemisphere were markedly reduced in patients. The decrease of lateralization correlated with increased severity of symptoms. In addition, both the overall functional activation in response to auditory stimulation and its asymmetry were reduced in the patients. Relatives had intermediate values between patients and controls on both structural and functional measures. This study provides added support for the idea that reduced hemispheric asymmetry is a biological risk factor for schizophrenia.

\section{Introduction}

In most healthy right handers, the left superior temporal lobe, which includes Heschl's gyrus (HG) and planum temporale (PT), is larger than the right hemisphere counterpart (Galaburda and Geschwind, 1981; Morosan et al., 2001; Zatorre et al., 2002; Chance et al., 2006), and differs from the right hemisphere in microanatomical structure at the columnar level (Hutsler and Galuske, 2003). Crow and colleagues (Crow et al., 1989; Crow, 1997) proposed that schizophrenia (SZ) results from a failure of normal cerebral lateralization and that this failure is genetically determined. Clinical support for this came from the intriguing observation that patients with temporal lobe epilepsy (TLE) who develop psychosis are more likely to have bilateral foci than TLE patients without psychosis (Flor-Henry, 1969). Abnormal hemispheric asymmetry may result in impaired speech processing,

\footnotetext{
Received Sept. 15, 2009; revised Dec. 1, 2009; accepted Dec. 15, 2009.

MRI was performed at the Frankfurt Brain Imaging Center, supported by the German Research Council and the German Ministry for Education and Research (Brain Imaging Center Frankfurt/Main, DLR 01G00203). V.0. was supported by the Scholarship for Graduate Students of Goethe University (Frankfurt, Germany) and Anna RotarskaJagiela by a doctoral studentship of the Josef Buchmann Foundation. We are grateful to Jutta Mayer and Robert Bittner for providing macros for statistical analysis. We are also grateful to Christian Altmann for help with programming the task. We thank the "Angehörigenverband Psychisch Kranker in Hessen" for the supporting help in recruiting.

Correspondence should be addressed to either of the following: Viola Oertel, Laboratory for Neurophysiology and Neuroimaging, Department of Psychiatry, Heinrich-Hoffmann-Straße 10, Goethe University, 60528 Frankfurt, Germany, E-mail: viola.oertel@kgu.de; or David E. J. Linden, School of Psychology, Bangor University, Bangor LL57 2AS, UK, E-mail: d.linden@bangor.ac.uk.

DOI:10.1523/JNEUROSCI.4575-09.2010

Copyright $\odot 2010$ the authors $\quad 0270-6474 / 10 / 302289-11 \$ 15.00 / 0$
}

which has been proposed to be a key cognitive factor in the manifestation of schizophrenia symptoms (Stephane et al., 2001; Frith, 2005). A specific deficit in the left hemisphere for schizophrenia was also suggested by the epilepsy data (Flor-Henry, 1969) (but see Nishida et al., 2006). The imaging evidence for reduced asymmetry in schizophrenia is mixed with some studies (e.g., Petty et al., 1995; Kwon et al., 1999; Kasai et al., 2003; Takahashi et al., 2006; Kawasaki et al., 2008), but not others (Kulynych et al., 1995; Barta et al., 1997; Frangou et al., 1997; Shapleske et al., 2001), reporting reduced left hemispheric gray matter volumes or reduction of normal asymmetry. One reason for these discrepancies may be that temporal lobe changes are progressive rather than static (Kasai et al., 2003; Gogtay et al., 2007), although the reduced asymmetry of brain activation while listening to speech reported by Razafimandimby et al. (2007) was stable at least over 21 months. However, experimental confounds, such as heterogeneous or small subject samples, inconsistent definitions of the anatomical structures, or differing anatomical quantifications may also explain the inconsistent evidence on asymmetry in schizophrenia.

The investigation of unaffected individuals who carry a genetic risk of schizophrenia may clarify this debate. Family, twin, and adoption studies suggest an important genetic role in the etiology for schizophrenia (McGuffin et al., 1995; Cardno et al., 1999; Bediou et al., 2007; Crow, 2007; Whalley et al., 2007). Hemispheric laterality in relatives of schizophrenia patients has mainly been investigated with functional imaging during language tasks. Sommer et al. (2004), Whyte et al. (2006), and Li et al. (2007) reported significantly de- 
Table 1. Sociodemographic and clinical variables of the schizophrenia patient group (SD)

\begin{tabular}{|c|c|c|c|c|c|}
\hline Diagnosis & $\begin{array}{l}\text { History of } \\
\text { hallucinations }\end{array}$ & Age of onset & Years of illness & Medication & $\begin{array}{l}\text { Global symptomatology } \\
\text { (PANSS; } n=16 \text { ) }\end{array}$ \\
\hline Paranoid schizophrenia (DSM-IV criteria 295.30 ${ }^{a}$ ) & $\begin{array}{l}\text { All: } n=16 \\
\text { Current episode: } n=8 \\
\text { Week of measurement: } n=4 \\
\text { Earlier episode: } n=8\end{array}$ & $24.43(6.63)$ & $13.71(6.87)$ & $\begin{array}{l}1-2 \text { atypical } \\
4 \text { atypical and typical }\end{array}$ & $\begin{array}{l}\text { Pos.: } 15.69(3.20) \\
\text { Neg.: } 15.13(1.78) \\
\text { Gen.: } 32.06(4.07) \\
\text { Sum: } 62.75(5.30) \\
\text { Hallucination score: } 3.08(1.40)\end{array}$ \\
\hline
\end{tabular}

${ }^{{ }^{A} \text { American Psychiatric Association (1994). Pos., Positive; Neg., negative; Gen., general. }}$

creased lateralization of activity in the inferior frontal gyrus, caused by higher right (Sommer et al., 2004; Whyte et al., 2006) or lower left (Li et al., 2007) frontal activation. Structural imaging has so far focused on medial temporal asymmetry (Keshavan et al., 2002). The only structural investigations of superior temporal asymmetry and genetic risk were based on computed tomography findings of enlargement of the left Sylvian fissure in patients and obligate carriers (Honer et al., 1995), and a negative finding comparing a significantly older relative group to controls (Frangou et al., 1997). There is presently no study that investigated both structural and functional asymmetry of auditory cortex in relatives [see Boos et al. (2007) and Lawrie et al. (2008)].

To provide a comprehensive study of hemispheric laterality across the spectrum of schizophrenia, we combined structural and functional magnetic resonance imaging (MRI) in patients and first-degree relatives. We expected parametrically reduced asymmetry of temporal lobe volume and function across the three subject groups, with lowest laterality values in patients and intermediate values in relatives. Furthermore, we assessed the contribution of asymmetry changes to psychopathology ratings to quantify the clinical relevance of temporal lobe asymmetry.

\section{Materials and Methods}

\section{Participants}

We included 16 SZ patients [mean age: 37.57 (SD: 7.84); range: $26-56 ; 7$ women, $9 \mathrm{men}$ ] diagnosed with paranoid schizophrenia according to DSM-IV criteria (American Psychiatric Association, 1994). All patients were inpatients of the Department of Psychiatry of Frankfurt University. All patients were treated with atypical antipsychotics, and four patients additionally with typical neuroleptic medication at the time of testing. To ensure that the results of our study were not due to a medication effect (Dazzan et al., 2005), we repeated the analysis for group differences on the structural measures without the four patients with typical medication. In addition, the duration of illness of the patients had to be $>5$ years [13.71 (6.87); range 5-31; view Table 1 for further details of the patients' psychopathology].

Sixteen first-degree relatives [41.87 (8.55); range: $26-59$; 9 women, 7 men] and 15 healthy controls [mean age: 39.31 (10.98); range: $26-56 ; 7$ women, $8 \mathrm{men}$ ] also participated in the experiment (Table 2). Contact to the relatives was established through participating patients, from a support group for relatives of SZ patients, and through newspaper articles, flyers, and advertisements in the hospital. The relatives were requested to bring a letter from the psychiatrist treating the patient of the affected family members to confirm the diagnosis. The relative group included parents $(n=6)$ and siblings $(n=10)$ of other SZ patients than those included in the study.

The control group was matched with the patient and relatives groups for handedness (all right handed; The Edinburgh Inventory) (Oldfield, 1971), age, sex, and parental education. None of the controls had any positive family history of schizophrenia. The patient group included $43.75 \%$ women, the relatives group included $56.25 \%$ women, and the control group included $46.6 \%$ women. Statistical tests $\left(\chi^{2}\right.$ test with group and gender as factors) showed that gender distribution was equal across groups $(p>0.05)$. Additional statistical tests (ANOVA, Scheffé post hoc contrast analyses) for differences between the groups regarding age, years of education, and parental education revealed no significant

\section{Table 2. Demographic data for all subject groups}

\begin{tabular}{lllll}
\hline & Patients & Controls & Relatives & Total \\
\hline$n$ & 16 & 15 & 16 & 47 \\
$\begin{array}{l}\text { Gender } \\
\quad \text { Women }\end{array}$ & 7 & 7 & 9 & 23 \\
$\quad$ Men & 9 & 8 & 7 & 24 \\
$\begin{array}{l}\text { Years of education (SD) } \\
\text { Parental education (years, SD) }\end{array}$ & $13.44(2.42)$ & $14.73(2.33)$ & $13.45(2.50)$ & $14.83(2.08)$ \\
$\quad$ Mother & $15.11(2.35)$ & $14.24(1.31)$ & $13.89(1.43)$ & $14.41(1.85)$ \\
$\quad$ Father & $15.89(3.12)$ & $15.31(2.45)$ & $14.95(1.89)$ & $15.38(2.13)$ \\
Age (years, SD) & $37.57(7.84)$ & $39.31(10.98)$ & $41.87(8.55)$ & $40.06(10.75)$ \\
Handedness & Right & Right & Right & All right \\
\hline
\end{tabular}

differences $(p>0.05)$. Exclusion criteria for control and relative participants were any psychiatric disorder including Axis I and Axis II disorders according to DSM-IV, left handedness, current drug abuse, neurological pathology, and inability to provide informed consent.

Neither personal reports nor auditory testing revealed any restrictions in the hearing of the subjects. We performed a number of tests to ensure that the functional activation results were not owed to impairment of hearing, speech disorders, or pathologies other than schizophrenia. Auditory analysis by an otologist revealed normal hearing. The anatomical MRI scans were reviewed by a neuroradiologist who did not find underlying pathology in the auditory cortex or surrounding areas. All subjects were native German speakers.

Participants were provided with a description of the study and gave written informed consent before participation. Experimental procedures were approved by the ethical board of the medical department of Goethe University, Frankfurt/Main, Germany.

\section{Assessment of psychopathology}

The Structured Clinical Interview for DSM-IV (Strukturiertes Klinisches Interview Psychischer Störungen) (Wittchen et al., 1996) was performed with schizophrenia patients and in controls and first-degree relatives. Relatives or control participants who met criteria for psychiatric or neurological disorders were excluded from the study. The final sample $(n=16)$ included only first-degree relatives without any psychiatric, neurological, or personality disorders. Current psychopathology was assessed using the Positive and Negative Symptom Scale (PANSS) (Kay et al., 1987).

All participants were screened for predisposition toward hallucinations with the Revised Hallucination Scale (RHS) (Morrison et al., 2002). An ANOVA with RHS as dependent variable and group as fixed factor was included in the Results.

All patients had a history of auditory hallucinations as assessed by the PANSS interview and a semistructured interview based on the criteria proposed by Aggernaes (1972) to assess the contents, phenomenology, severity, and occurrence of hallucinations in more detail. The last period of auditory hallucinations ranged from $5 \mathrm{~d}$ to 8 months before the scanning. None of the patients reported any hallucinations while they were scanned.

\section{Functional imaging: stimulus material}

Functional magnetic resonance imaging (fMRI) of acoustic stimulation consisted of three experimental runs with similar stimuli presented in a random order across the subjects. Each run consisted of 13 fragments of spoken texts of three categories: "weather," "flowers," and "garden." Periods of acoustic stimulation varied between 15, 20, and $30 \mathrm{~s}$, each alternated with an interstimulus interval (rest condition) of $15 \mathrm{~s}$. 
The goal was to create acoustic material to examine global activation and that closely matched the temporal features of auditory hallucinations, while at the same time preventing potential emotional bias toward the contents of the material (David, 1999). The texts were recorded digitally and edited on a personal computer with standard computer software (RealPlayer, RealNetworks; Presentation, Neurobehavioral Systems). During the fMRI examination, the stimuli were delivered at constant sound pressure level through a custom-made pneumatic sound transmission device with headphones that accurately preserve tone frequencies and attenuate scanner noise.

\section{Data acquisition and image processing}

All subjects underwent functional and anatomical imaging on a Siemens Magnetom Allegra 3 tesla MRI system (Siemens Medical Systems) at the Frankfurt University Brain Imaging Center, Frankfurt/Main, Germany. Each session began with a functional scan (auditory stimulation; EPI sequence, 480 volumes, voxel size: $3.3 \times 3.3 \times 5.0 \mathrm{~mm}^{3}$, TR $=1000 \mathrm{~ms}$, $\mathrm{TE}=30 \mathrm{~ms}, 16$ slices, slice thickness $=5 \mathrm{~mm}$, dist. factor: $10 \%$, interslice time $62 \mathrm{~ms}$, flip angle: $60^{\circ}$ ). We synchronized stimulus presentation with the fMRI sequence at the beginning of each trial. For anatomical measurement, we acquired a high-resolution T1-weighted MDEFT sequence (Deichmann et al., 2004) $\left(176\right.$ slices, $\left.1 \times 1 \times 1 \mathrm{~mm}^{3}\right)$ covering the whole brain.

During the functional scan, 13 blocks of acoustic stimulation alternated with a baseline condition without acoustic stimulation (except for the constant scanner noise). Participants were scanned with eyes open in darkness and instructed to look at a white fixation cross, and to listen attentively to each stimulus. During the stimulus periods, the patients did not engage in overt speech. The participants were asked to press a button with their left index finger at the onset of a spoken voice and to press the button again when it stopped. For each subject, a stimulation protocol was generated from the button press time points. No participant missed any of the onsets or offsets of speech periods, indicating that all groups were equally aware of the auditory stimulation. The sound pressure level of the voices was well above that of the ambient noise of the MRI scanner. In a preexperiment with 15 volunteers, we delivered a series of fragments of the texts to adjust the sound pressure level, allowing a comfortable hearing level and a clear sound perception in the session. Although the continuous sampling of MRI signals means that the neural effects of scanner background noise added to the effects of auditory stimulation (Gaab et al., 2007a,b), this interference is unlikely to differ between groups or hemispheres. The whole session lasted $\sim 25 \mathrm{~min}$.

\section{Statistical analysis}

Functional imaging: preprocessing. We preprocessed and analyzed the fMRI data using the BrainVoyager software, versions 2000 and QX (Brain Innovation). Further analysis was done with custom-written routines in Matlab (MathWorks) software. For the functional data, we applied the following preprocessing steps: slice-time correction, motion correction, spatial smoothing using a Gaussian kernel of $4 \mathrm{~mm}$ full-width at half-maximum, linear trend removal, and high-pass temporal filtering of three cycles per time course. Coregistration of the functional data to the anatomical scans was performed with automated routines in BrainVoyager. We transformed the three-dimensional (3D) anatomical scans into Talairach space (Talairach and Tournoux, 1988) using a 12-point affine transformation as implemented in the BrainVoyager software, and subsequently used the parameters for this transformation to transform the coregistered functional data. We then resampled the 3D functional dataset to a voxel size of $1 \times 1 \times 1 \mathrm{~mm}^{3}$.

We identified auditory cortex using two complementary approaches: using a probabilistic map of primary auditory cortex, which anatomically comprises HG (Penhune et al., 1996; Rademacher et al., 2001), and manual anatomical segmentation of HG and PT. The probabilistic map indicates the probability for any anatomical voxel to belong to left or right Heschl's gyrus with respect to an anatomically averaged template in healthy participants (Rademacher et al., 2001). In our study, volumes of interest (VOIs) of left and right HG were created by setting the probability level at a minimum of $20 \%$ to capture the high anatomical and functional variability of the auditory cortices [Talairach coordinates for center of mass (CoM) of left auditory cortex: $x=-40, y=-20, z=8$, number of voxels $(\mathrm{NoV})=10,021$; right CoM: $x=45, y=-13, z=10$, $\mathrm{NoV}=9199$ ]. Note that this procedure resulted in a single general (i.e., subject and group unspecific) VOI for left and for right auditory cortex, which was used to blindly sample functional data for further analysis. This procedure was previously used to investigate functional connectivity of auditory cortex in healthy controls and hallucinating SZ patients (van de Ven et al., 2004, 2005). For the second procedure, cortical regions of HG and PT were segmented from individual anatomical images of the subjects using a combination of manual and automated segmentation procedures, which are further described below (Anatomical imaging: preprocessing and analysis).

Functional imaging: analysis. The stimulation protocol was convolved with a hemodynamic response function (Boynton et al., 1996) to generate the predictor function for acoustic stimulation, which was fit to the functional data using the general linear model (GLM). In addition, we defined group as a between-subject factor. Statistical results were corrected for multiple comparisons using the false discovery rate (FDR) (Genovese et al., 2002). An F-statistic was calculated for each voxel to create whole-brain activation maps to find cortical regions sensitive to acoustic stimulation. Activation maps were created for all participants to identify regions significantly activated during speech perception (thresholded at $p=0.05$, FDR corrected). For the region of interest $(\mathrm{ROI}=$ all suprathreshold voxels in the functional map for a VOI $)$ analysis, the $\beta$ values (i.e., predictor fit to each voxel's time series) of all individuals were extracted and imported into SPSS 12.0 for a $3 \times 2$ mixed-effects RMANOVA with between-subject factor group (controls, first-degree relatives, SZ patients), within-subject factor hemisphere (left, right), and age, gender, and years of education as between-subject covariates (see Table 3). We performed these analyses for the probabilistic auditory cortex VOI and the individually segmented HG and PT VOIs, which were normalized in Talairach space across participants (Fig. 1).

Furthermore, we calculated functional lateralization indices (LIs) for auditory cortex $\left(\mathrm{fLI}^{\mathrm{a}}\right), \mathrm{HG}\left(\mathrm{fLI}^{\mathrm{HG}}\right)$, and PT ( $\mathrm{fLI}^{\mathrm{PT}}$ ) and correlated these indices with the severity of symptoms of the SZ patients. The LI was calculated as the difference between the number of active voxels within a specific region (e.g., VOIs of HG, PT, or auditory cortex) in the left and in the right hemisphere divided by the total sum of activated voxels within the VOIs of both hemispheres [i.e., $\mathrm{LI}=(\mathrm{left}-$ right $) /($ left + right $)]$. The LI ranges from -1 to 1 , and a negative LI implies relatively more right hemispheric activation during the task, whereas a positive LI implies more left hemispheric activation.

In addition, we computed bivariate correlation analysis (Pearson product moment correlation; corrected for multiple comparisons) between the lateralization indices ( $\mathrm{fLI}^{\mathrm{PT}}, \mathrm{fLI}^{\mathrm{HG}}, \mathrm{fLI}^{\mathrm{a}}$ ) and the individual psychopathology (PANSS, RHS), and between the functional and the anatomical LIs (see below).

Anatomical imaging: preprocessing and analysis. We conducted a morphometric analysis of the HG and the PT. The high-resolution T1weighted MDEFT sequence (Deichmann et al., 2004) (176 slices, $1 \times 1 \times 1$ $\mathrm{mm}^{3}$ ) was used for delineating and measuring the HG and the PT. Preprocessing of the data included horizontal alignment (in coronal view) of the plane defined by the anterior and posterior commissures (AC-PC plane). The HG and PT gray matter regions of interest (ROIs) were manually outlined without knowledge of diagnosis using a software package for cortical segmentation (vmr-segmenter) (Schönmeyer et al., 2006). The landmarks for delineating HG and PT gray matter have been described by Hirayasu et al. (2000). For initial identification of HG and PT, HG and PT gray matter was traced with the vmr-segmenter (http://www.bic.uni-frankfurt.de/bv-tools/) on coronal images to the end of the Sylvian fissure, and the gray matter of the ascending ramus of the Sylvian fissure was also included. Our definition of the HG and PT followed the work of Kasai et al. (2003), who included HG and PT proper and its parietal extension. Finally, sagittal MRIs were used to check and confirm HG and PT boundaries. After drawing, the HG and PT ROIs could be viewed in any plane and as a three-dimensional object for further editing. For interrater reliability, raters (V.O., C.K., A.R.-J.) blinded to group membership independently drew ROIs. The intraclass correlation coefficient of the left (right) PT gray matter regions was $0.96(0.94)$. 
Table 3. Differences in auditory cortex activation (extent in number of suprathreshold voxels and amplitude as estimated by the $\boldsymbol{\beta}$ value of the cluster mean) across groups

\begin{tabular}{|c|c|c|c|c|}
\hline & $\begin{array}{l}\text { SZ PAT: Talairach coord. } \\
\text { (no. of voxels; } \beta \text { value) }\end{array}$ & $\begin{array}{l}\text { REL: Talairach coord. } \\
\text { (no. of voxels; } \beta \text { value) }\end{array}$ & $\begin{array}{l}\text { CON: Talairach coord. } \\
\text { (no. of voxels; } \beta \text { value) }\end{array}$ & $\begin{array}{l}\text { Significance of contrasts } \\
\text { for } \beta \text { values }\end{array}$ \\
\hline Left auditory cortex & $-50,-16,5(1145 ; 0.55)$ & $-46,-21,8(4718 ; 0.63)$ & $-46,-18,8(5758 ; 0.72)$ & $\begin{array}{l}F_{(2,44)}=8.72, p=0.01 \\
\text { PAT/REL: } p=0.01 \\
\text { CON/REL: } p=0.05 \\
\text { PAT/CON: } p=0.04\end{array}$ \\
\hline Right auditory cortex & $49,-13,6(879 ; 0.55)$ & $51,-13,8(2100 ; 0.81)$ & $50,-10,7(3021 ; 0.87)$ & $\begin{array}{l}F_{(2,44)}=4.98, p=0.01 \\
\text { Interaction group } \times \text { hemisphere: } F_{(2,44)}=13.94, p<0.01 \\
\text { PAT/REL: } p=0.04 \\
\text { PAT/CON: } p=0.03 \\
\text { REL/CON: } \text {..S. }\end{array}$ \\
\hline Left HG & $-49,-19,8 ;(343 ; 0.56)$ & $-49,-18,3(1609 ; 0.76)$ & $-48,-25,8(4584 ; 0.81)$ & $\begin{array}{l}F_{(2,43)}=4.04, p=0.025 \\
\text { PAT/REL: } p=0.01 \\
\text { PAT/CON: } p=0.03 \\
\text { REL/CON: } \text { n.s. }\end{array}$ \\
\hline Right HG & $52,-9,5(432 ; 0.58)$ & $50,-12,0(862 ; 0.66)$ & $-52,14,5(2313 ; 0.79)$ & $\begin{array}{l}F_{(2,44)}=3.28, p=0.04 \\
\text { PAT/REL: } n . s . \\
\text { PAT/CON: } p=0.04 \\
\text { REL/CON: } \text { n.s. }\end{array}$ \\
\hline Left PT & $-52,-21,9(954 ; 0.48)$ & $-48,-20,3(1938 ; 0.55)$ & $-48,-26,8(4261 ; 0.77)$ & $\begin{array}{l}F_{(2,44)}=9.66, p<0.01 \\
\text { PAT/REL: n.s. } \\
\text { PAT/CON: } p<0.01 \\
\text { REL/CON: } p<0.01\end{array}$ \\
\hline Right PT & $58,-18,4(688 ; 0.54)$ & $52,-21,3(1313 ; 0.73)$ & $54,-20,6(2649 ; 0.85)$ & $\begin{array}{l}F_{(2,44)}=5.22, p<0.01 \\
\text { Hemisphere: } F_{(2,44)}=10.79, p<0.01 \\
\text { PAT/REL: } \text { n.s. } \\
\text { PAT/CON: } p=0.01 \\
\text { REL/CON: } \text { n.s. }\end{array}$ \\
\hline
\end{tabular}

PAT, Patients; REL, relatives; CON, controls; coord., coordinates. The right column reports the ANOVA on the $\beta$ values.

For the left (right) HG, the intraclass correlation coefficient was 0.93 (0.95). Furthermore, interrater reliability (computed by using all of the slices from five randomly selected brains and measured by each of the three raters) was $0.96-0.98$ for all structures. In addition, intrarater reliability for five other, randomly selected brains was very good (rater 1: 0.93 , rater 2: 0.96 , rater $3: 0.97)$. The lateralization index for $\mathrm{HG}\left(\mathrm{LI}^{\mathrm{HG}}\right)$ and PT $\left(\mathrm{LI}^{\mathrm{PT}}\right)$ volume (in $\mathrm{mm}^{3}$ ) was computed as for the functional data (described in previous section). Figure 1 shows the interindividual consistency of the anatomical segmentation in Talairach space.

Intracranial volume (ICV) (Prvulovic et al., 2002) was measured using a region-growing intensity-based thresholding segmentation implemented in the BrainVoyager software with a segmentation limit set at the brainstem. The sum of all marked voxels was used as the intracranial volume score. In addition, the total brain volume (BV) was measured with the same semiautomated segmentation method using BrainVoyager (for details, see RotarskaJagiela et al., 2008).

We performed a $3 \times 2$ mixed-effects

RMANOVA with between-subject factor group, within-subject factor hemisphere and ICV, age, gender, years of illness, years of education, age of onset as between-subject covariates on the HG and PT volumes. We also performed correlation (corrected for multiple comparisons with Bonferroni correction) analyses to assess the relationship between HG and PT volume and individual psychopathology.

Similarly, we performed ANCOVA on the $\mathrm{LI}^{\mathrm{PT}}$ and $\mathrm{LI}^{\mathrm{HG}}$ with group as between-subject factor and age, gender, years of illness, years of education, and age of onset as covariates. Finally, LIs were correlated with the PANSS scores.

In addition, we computed the chlorpromazine equivalence doses for the patients' antipsychotic medication (Woods, 2003). Individual doses ranged from 200 to $1500 \mathrm{mg} / \mathrm{d}$ [mean: 613.33 (399.31)]. We computed the correlation between the chlorpromazine equivalents and the anatomical and functional indices to investigate a possible medication effect (Pearson bivariate correlation, two-tailed).

\section{Results}

Functional imaging: effect of auditory stimulation

Group data were superimposed on a Talairach-transformed MNI template [courtesy of the Montreal Neurological Institute (MNI)]. Significant activation (thresholded at $p=0.05$, FDR corrected for multiple tests; minimum cluster size $=200 \mathrm{~mm}^{3}$ ) 


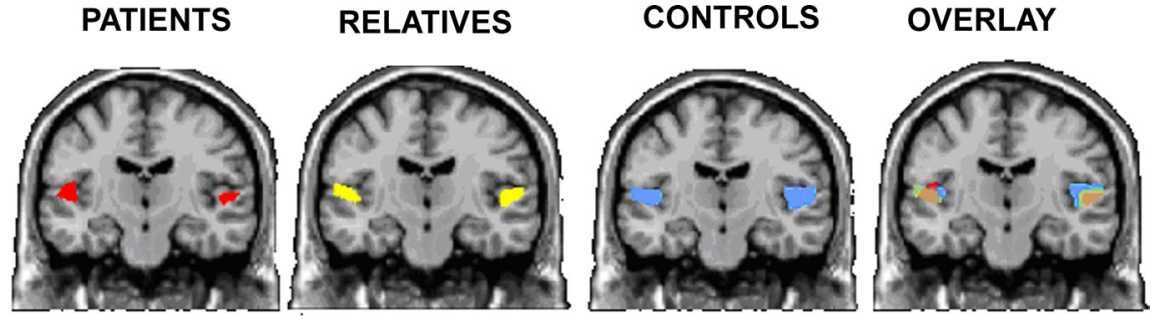

Figure 2. Functional imaging results. Suprathreshold voxels ( $p<0.05$, FDR corrected for multiple comparisons) for auditory stimulation in the fMRI activation maps. From left to right, SZ patients, first-degree relatives, controls, and overlay map are shown. Color code (RGB system): red, SZ patients; yellow, first-degree relatives; blue, controls; green, overlay first-degree relatives/ controls; orange, overlay SZ patients/first-degree relatives; purple, overlay controls/SZ patients; gray, overlay SZ patients/firstdegree relatives/controls.

during acoustic stimulation was found in primary and higher auditory areas (Fig. 2). Across all subjects, the highest activation was found bilaterally in the transverse temporal gyrus (Heschl's gyrus; BA 41) and the planum temporale (BA 42). The activated areas are known to be involved in auditory processing (e.g., Sommer et al., 2001; Hickok and Poeppel, 2007).

Auditory cortex activation, as sampled using the probabilistic VOI, was significantly different across groups (Table 3), with controls showing the highest and most extensive activation, followed by relatives and patients (left auditory cortex: $F_{(2,44)}=$ $8.72, p=01$; right auditory cortex: $\left.F_{(2,44)}=4.98, p=0.01\right)$. The interaction effect hemisphere $\times$ group was also significant $\left(F_{(2,44)}=\right.$ 13.94, $p<0.01)$. The Scheffé post hoc contrast analysis showed significant contrasts between the SZ patients and the other groups (all $p<0.05$ ). The contrast between the relatives and the controls in the left hemisphere was nonsignificant $(p>0.05)$. Additionally, the analyses showed significant contrasts between the controls and the SZ patients $(p=0.03)$ and the relatives and the SZ patients in the right hemisphere $(p=0.04)$. The contrast between the controls and the relatives in the right hemisphere was nonsignificant $(p>0.05)$.

The functional activation in the individually defined left and right HG and PT followed the same pattern with significant differences across groups in HG (left HG: $F_{(2,44)}=4.04, p=0.02$, right HG: $\left.F_{(2,44)}=3.28, p=0.04\right)$ and PT (left PT: $F_{(2,44)}=9.66$, $p<0.01$, right PT: $F_{(2,44)}=5.22, p<0.01$ ) (for further details, view Table 3 ), showing that controls had the most extensive activation in PT and HG of both hemispheres, followed by relatives and patients. The Scheffé post hoc contrast analyses confirmed this pattern with significant contrasts between patients and controls in the left and right PT and HG $(p<0.05)$. More specifically, controls showed greater activity in left PT compared to the relatives $(p<0.01)$, and relatives showed greater activity in left HG compared to patients $(p=0.01)$. The interaction of hemisphere $X$ group in HG and PT separately was not significant, but a significant effect of hemisphere was found for the PT $\left(F_{(2,44)}=\right.$ $10.79, p<0.01)$. In contrast, the analysis of the HG data revealed no significant effect of hemisphere. All other computed single contrasts were nonsignificant.

\section{Functional imaging: lateralization}

The functional lateralization indices for the auditory cortex map $\left(\mathrm{fLI}^{\mathrm{a}}\right)$ showed highest left lateralized activity for the controls [mean (SD) $\left.\mathrm{fLI}^{\mathrm{a}}=0.38(0.09)\right]$, followed by decreased left lateralization for the relatives $[0.31(0.13)]$ and the patients $\left[\mathrm{fLI}^{\mathrm{a}}{ }^{\mathrm{a}}: 0.11\right.$ (0.08) ]. The ANCOVA computed with $\mathrm{fLI}^{\mathrm{a}}$ as dependent variable and group as between-subject factor showed a significant main effect for group $\left(F_{(2,38)}=4.68, p=0.04\right)$. Scheffé post hoc contrast analysis showed significant differences for the contrast SZ patients versus controls $(p<0.05)$, but the other contrasts were not significant (Fig. 3).

The functional lateralization indices for the HG ( $\mathrm{fLI}^{\mathrm{HG}}$ ) and PT ( $\mathrm{fLI}^{\mathrm{PT}}$ ) also showed a similar pattern of decreased left lateralization from controls [ $\mathrm{fLI}^{\mathrm{HG}}$ : 0.05 (0.013); fLI ${ }^{\mathrm{PT}}$ : $\left.0.11(0.010)\right]$, followed by the relatives $\left[\mathrm{fLI}^{\mathrm{HG}}: 0.01(0.016)\right.$; $\mathrm{fLI}^{\mathrm{PT}}$ : $0.05(0.018)]$ and the patients $\left[\mathrm{fLI}^{\mathrm{HG}}\right.$ : -0.01 (0.017); fLI ${ }^{\mathrm{PT}}$ : -.03 (0.026)]. The ANCOVAs computed with the fLI ${ }^{\text {PT }}$ and $\mathrm{fLI}^{\mathrm{HG}}$ separately as dependent variables and group as between-subject factor showed significant main effects of group $\left(\mathrm{fLI}^{\mathrm{HG}}: F_{(2,43)}=8.78\right.$, $\left.p=0.03 ; \mathrm{fLI}^{\mathrm{PT}}: F_{(2,43)}=4.53, p=0.04\right)$. The Scheffé post hoc contrasts revealed significant contrasts between SZ patients and controls for $\mathrm{fLI}^{\mathrm{HG}}$ and $\mathrm{fLI}^{\mathrm{PT}}(p<0.05)$, and a significant contrast between relatives and controls for $\mathrm{fLI}^{\mathrm{PT}}(p<0.05)$. The contrast between relatives and controls for the $\mathrm{fLI}^{\mathrm{HG}}$ was nonsignificant $(p>0.05)$.

\section{Functional imaging: correlation with symptoms}

The mean total score (SD) of the PANSS at the time of scanning was 62.75 (5.30), and the general score was 32.06 (4.07). The mean total score on the positive subscale was 15.69 (3.20), and the mean total score on the negative subscale was 15.13 (1.78). The mean score on item 3 (hallucinations) was 3.08 (1.40). The score of the positive symptoms was calculated without the hallucination score to enable subsequent separate correlations. All patients had a history of hallucinations, eight had experienced auditory hallucinations in the current episode of their illness, but not during the scan, whereas eight patients had experienced auditory hallucinations only in a previous episode of illness.

We found a significant negative correlation between the fLI ${ }^{\mathrm{a}}$ of the SZ patients and the total score of the PANSS $(r=-0.48$, $p<0.05)$. The correlation between the lateralization indices and the severity of negative symptoms was not significant. Conversely, we found a significant negative correlation between the severity of positive symptoms and the lateralization indices of the auditory cortex $\left(\mathrm{fLI}^{\mathrm{a}}\right)$, the PT $\left(\mathrm{fLI}^{\mathrm{PT}}\right)$, and $\mathrm{HG}\left(\mathrm{fLI}^{\mathrm{HG}}\right)\left(\mathrm{fLI}^{\mathrm{a}}-\right.$ PANSS-POS: $r=-0.37, p=0.03$; $\mathrm{fLI}^{\mathrm{PT}}-$ PANSS-POS: $r=$ $-0.48, p<0.05$; $\mathrm{fLI}^{\mathrm{HG}}-$ PANSS-POS: $r=-0.41, p<0.05$ ). Similarly, a significant negative correlation between the severity of auditory hallucinations and the lateralization was found in the auditory cortex and in the planum temporale ( $\mathrm{fLI}^{\mathrm{a}}-$ hallucination score: $r=-0.67, p<0.05$; $\mathrm{fLI}^{\mathrm{PT}}-$ hallucination score: $r=$ $-0.61, p=0.03)$. In sum, lower relative activation in the left hemisphere was associated with more severe positive symptoms and auditory hallucinations (Fig. 4).

The mean total score of the RHS was lowest for the control group [23.80 (3.97)], followed by the relatives [27.87 (6.32)] and the patients with the highest score on this scale [33.56 (5.82)]. These group differences were significant $\left(F_{(2,43)}=12.48, p<\right.$ $0.01)$. The Scheffé post hoc contrast analyses revealed significant contrasts between the patients and the relatives $(p=0.02)$ as well as the patients and the controls $(p<0.01)$. A significant negative correlation was found between the lateralization of the PT and the RHS scores $(r=-0.43, p=0.03)$. No significant correlation was found between the lateralization of the HG and the RHS. 
a HG Volume

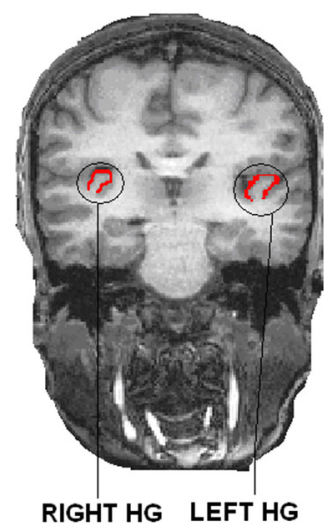

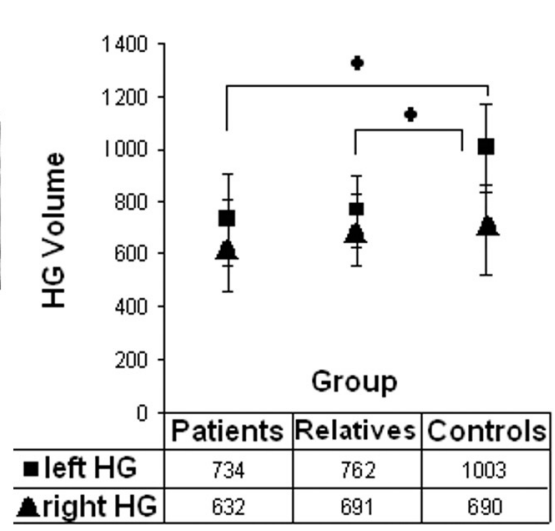

b

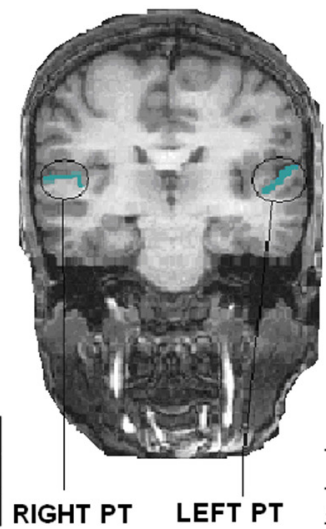

PT Volume

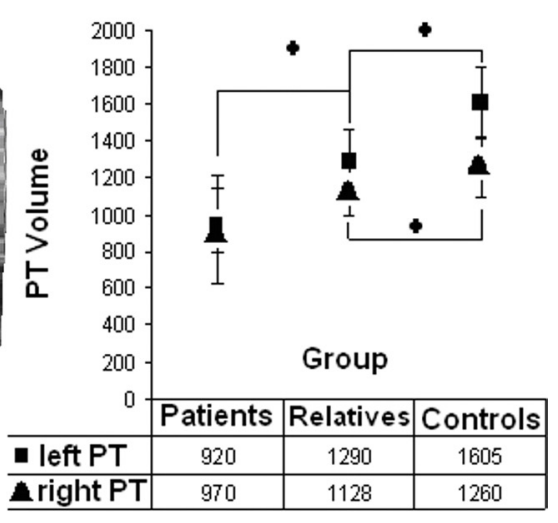

Figure 3. Anatomical segmentation results. $\mathrm{HG}$ and PT volume in the different subject groups (patients, relatives, controls). The squares represent the left HG/PT, the triangles the right HG/PT. $\boldsymbol{a}$ shows the values for $\mathrm{HG}, \boldsymbol{b}$ for PT. Asterisks denote significant group differences ( $p<0.05$ ).

\section{Structural imaging: morphometric} analysis of planum temporale and Heschl's gyrus

RMANOVA of PT gray matter volumes showed significant main effects of hemisphere (left vs right PT: $F_{(1,45)}=3.98, p<$ $0.01)$ and group $\left(F_{(2,44)}=18.49, p<0.01\right)$ and a significant group $\times$ hemisphere interaction $\left(F_{(2,44)}=6.53\right.$, all $\left.p<0.01\right)$ (see Table 4). The post hoc Scheffé single contrast analysis showed significant differences between all groups $(p<0.01)$ in the left hemisphere. Similarly, the mean gray matter volume of the right PT showed a continuum with SZ patients having a smaller volume $\left(970 \mathrm{~mm}^{3}\right)$, followed by the relative group $\left(1128 \mathrm{~mm}^{3}\right)$ and the control group $\left(1260 \mathrm{~mm}^{3}\right)$. Post hoc Scheffé contrast analyses revealed a significant difference between patients and controls only $(p<0.01)$. The covariates $\mathrm{BV}, \mathrm{ICV}$, age, gender, years of illness, education, and age of onset, which were used in the current analysis, showed no significant influence on the PT volume.

Analysis of the lateralization index of $\mathrm{PT}\left(\mathrm{LI}^{\mathrm{PT}}\right)$ further corroborated the findings of gray matter volume differences across hemispheres and groups. Specifically, we found a significant main effect of group $\left(F_{(2,44)}=3.69, p=0.03\right)$, in which $\mathrm{LI}^{\mathrm{PT}}$ showed a continuum of decreasing left lateralization from the control group $\left[\mathrm{LI}^{\mathrm{PT}}=0.12(0.08)\right]$, followed by the relatives $[0.07(0.016)]$ and the patients $[0.01(0.01)]$, which is similar to the continuum found for the functional data. Post hoc contrast analyses revealed a significant difference between patients and controls $(p=0.03)$. The covariates had no significant effect on the LI differences.

Left PT gray matter volume correlated negatively with the hallucination score of the PANSS $(r=-0.60, p=0.02)$ and the general psychopathology subscale $(r=-0.52, p<0.05)$. The $\mathrm{LI}^{\mathrm{PT}}$ correlated negatively with the severity of positive symptoms $(r=-0.49, p<0.05)$, the hallucination score of the

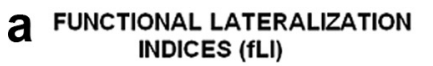

b CORRELATION BETWEEN PSYCHOPATHOLOGY (PANSS)
AND FUNCTIONAL LATERALIZATION INDICES (fLI)

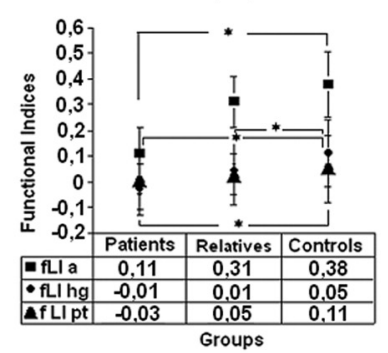

C anatomical lateralization
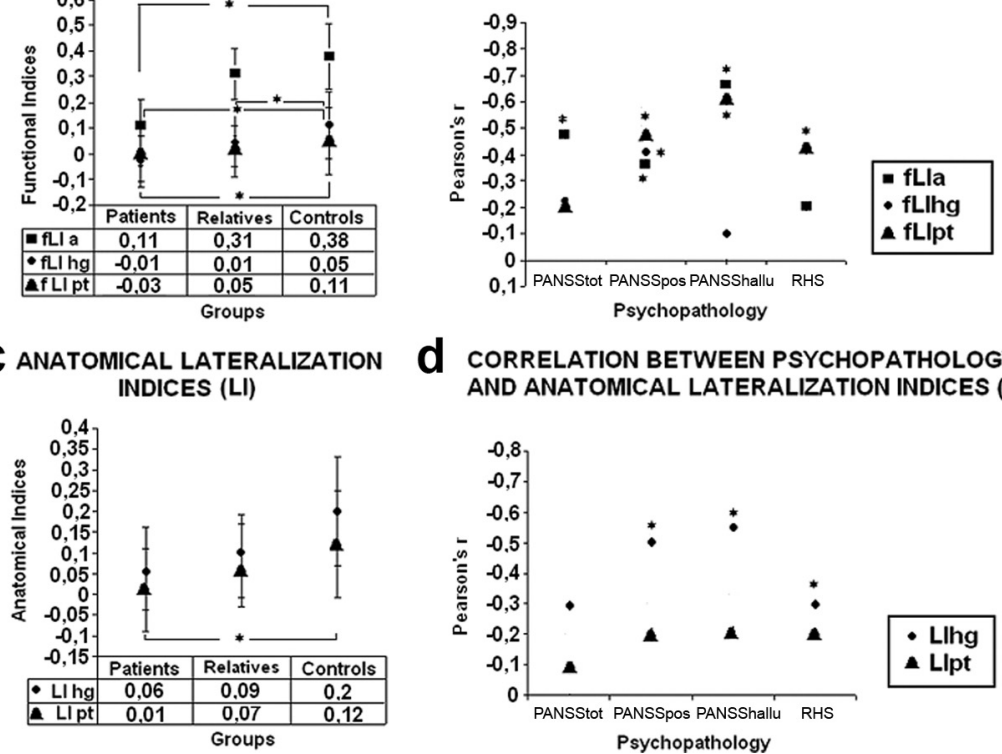

\section{d}

CORRELATION BETWEEN PSYCHOPATHOLOGY (PANSS) AND ANATOMICAL LATERALIZATION INDICES (LI)

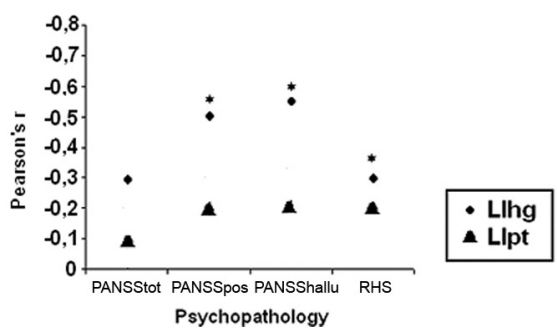

Figure 4. Functional and anatomical lateralization indices for the different groups and results of correlation analyses with the PANSS and RHS scores. Asterisks denote significant group differences $(\boldsymbol{a}, \boldsymbol{c})$ or correlations $(\boldsymbol{b}, \boldsymbol{d})(p<0.05$; Bonferroni corrected). $\boldsymbol{a}$, Group differences of fLI for the whole auditory cortex (fLla) (squares), HG (fLlhg) (circles), and PT (fLIpt) (triangles). $\boldsymbol{b}$, Correlations of fLIs with the total PANSS score (PANSStot) and positive (PANSSpos) and hallucination (PANSShallu) subscores and the scores on the Revised Hallucination Scale (RHS). c, Group differences of LI for HG (LIhg) (circles) and PT (LIpt) (triangles). $\boldsymbol{d}$, Correlations of $\mathrm{LI}$ values with the symptom scores (see $\boldsymbol{b}$ ).

PANSS ( $\mathrm{LI}^{\mathrm{PT}}-$ hallucination score: $r=-0.55, p<0.05$ ) and the RHS scores $(r=-0.30, p=0.04)$. In sum, lower relative volume in the left hemisphere was associated with more severe positive symptoms and auditory hallucinations (Fig. 4).

RMANOVA with covariates of HG gray matter volumes showed a significant main effect of group $\left(F_{(2,44)}=3.81 p=0.04\right)$ but not of hemisphere $\left(F_{(1,45)}=1.56, p>0.05\right)$. The interaction group $\times$ hemisphere was significant $\left(F_{(2,44)}=4.24, p=0.02\right)$. Mean gray matter volumes of left HG differed significantly between groups $\left(F_{(2,44)}=3.81 p=0.02\right)$. Post hoc Scheffé single contrast analysis showed a continuum of patients [734 (173)], relatives [762 (135)], and controls [1003 (367)] with significant differences between the patients and the controls $(p=0.02)$ and 
Table 4. ICV, volume of the PT, volume of HG, and the LI across subject groups (SD)

\begin{tabular}{|c|c|c|c|c|c|}
\hline & PAT & REL & $\mathrm{CON}$ & RMANOVA & Post hoc \\
\hline ICV & $2,039,035(200,150)$ & $1,952,364(180,099)$ & $2,054,205(234,738)$ & $F_{(2,44)}=0.84, p=0.44$ & $\begin{array}{l}\text { PAT/CON: } p=0.98 \\
\text { PAT/REL: } p=0.58 \\
\text { CON/REL: } p=0.48\end{array}$ \\
\hline \multirow[t]{6}{*}{ PT } & Left: 934 (190) & Left: 1292 (263) & Left: 1605 (268) & Hemisphere: $F_{(1,45)}=3.98, p<0.01$ & Left: \\
\hline & Right: 970 (183) & Right: 1128 (311) & Right: 1260 (191) & Group: $F_{(2,44)}=18.49, p<0.01$ & PAT/CON: $p<0.01$ \\
\hline & & & & Interaction hemisphere $\times$ group: $F_{(2,44)}=6.53, p<0.01$ & $\begin{array}{l}\text { PAT/REL: } p<0.01 \\
\text { CON/REL: } p<0.01 \\
\text { Right: }\end{array}$ \\
\hline & & & & & $\mathrm{PAT} / \mathrm{CON}: p<0.01$ \\
\hline & & & & & PAT/REL: $p=0.18$ \\
\hline & & & & & CON/REL: $p=0.41$ \\
\hline \multirow[t]{4}{*}{ HG } & Left: 734 (173) & Left: 762 (135) & Left: 1003 (367) & Hemisphere: $F_{(1,44)}=1.56, p>0.05$ & Left: \\
\hline & Right: 632 (195) & Right: 691 (233) & Right: 690 (308) & Group: $F_{(2,44)}=3.81, p=0.04$ & $\mathrm{PAT} / \mathrm{CON}: p=0.02$ \\
\hline & & & & Interaction hemisphere $\times$ group: $F_{(2,44)}=4.24, p=0.02$ & $\begin{array}{l}\text { PAT/REL: } \text { n.S. } \\
\text { REL/CON: } p=0.04 \\
\text { Right: }\end{array}$ \\
\hline & & & & & All $p$ values $>0.05$ \\
\hline \multirow[t]{3}{*}{$\mathrm{LI}^{\mathrm{PT}}$} & $0.01(0.01)$ & $0.07(0.01)$ & $0.12(0.08)$ & $F_{(2,44)}=3.69, p=0.03$ & $\mathrm{PAT} / \mathrm{CON}: p=0.03$ \\
\hline & & & & & PAT/REL: $p=0.34$ \\
\hline & (2006) & & & & CON/REL: $p=0.61$ \\
\hline $\mathrm{Ll}^{10}$ & $0.06(0.02)$ & $0.09(0.01)$ & $0.20(0.02)$ & $F_{(2,44)}=1.45, p=0.05$ & All contrasts n.s. \\
\hline
\end{tabular}

PAT, Patients; REL, relatives; CON, controls. Absolute volumes are given in cubic millimeters.

the relatives and the controls $(p=0.04)$. Right HG gray matter volumes did not significantly differ between groups [patients: 632 (195); relatives: 691 (233); controls: $690(308) ; F_{(3,43)}=1.04$, $p>0.05]$.

In addition, the covariates BV, ICV, age, gender, years of illness, education, age of onset, which were used in the current analysis, showed no significant influence on the HG volume. Analysis of the $\mathrm{LI}^{\mathrm{HG}}$ showed a similar effect of decreasing left lateralization between controls $[0.20(0.02)]$, relatives $[0.09$ $(0.01)]$, and patients $[0.06(0.02)]$. However, this effect did not reach significance. Left $\mathrm{HG}$ gray matter volume was negatively correlated with the severity of positive symptoms $(r=-0.42, p<$ $0.05)$. All other correlations between $\mathrm{HG}$ gray matter volume and the psychopathological symptoms were nonsignificant.

In addition, we calculated the bivariate correlation between the functional and anatomical LIs. Anatomical and functional LIs were significantly correlated for PT $(r=0.48, p=0.04)$, but only marginally significantly for $\mathrm{HG}(r=0.27, p=0.06)$.

\section{Analysis of medication effects and power calculation}

The correlations between the chlorpromazine equivalence doses of the patients and functional (left and right functional activation in $\mathrm{HG}$ and PT) and anatomical data (left and right volume in HG and PT) were nonsignificant (all $r$ values $<0.34$, all $p$ values $>0.12$ ) (Table 5). In addition, we repeated the analysis for group differences on the structural measures without the four patients with typical medication. Here the results conformed to those found with these patients included.

We computed power calculations on the morphometric findings of the PT and HG (Cohen, 1992) for any contrast (controls vs patients/controls vs relatives/relatives vs patients) (view Table 6). These calculations revealed effect sizes between $r=0.50$ and $r=$ 0.68 for left and right PT and left and right HG.

\section{Discussion}

We combined functional and structural imaging to assess the temporal lobe asymmetry changes of patients with schizophrenia, first-degree relatives, and healthy controls. Our results demonstrate a parametric reduction of the normal L $>$ R asymmetry
Table 5. Bivariate correlation analyses in the patient group (Pearson correlation; $p<0.05$; uncorrected) between patients' chlorpromazine equivalents and the structural (left PT, right PT, left HG, right HG) and functional (left HG, right HG, left PT, right PT) MRI measures

\begin{tabular}{ccc}
\hline & Anatomical & Functional \\
\hline Left PT & & \\
$r$ & -0.19 & 0.28 \\
$p$ & 0.24 & 0.31 \\
Right PT & & \\
$r$ & -0.14 & -0.14 \\
$p$ & $p>0.5$ & $p>0.5$ \\
Left HG & & \\
$r$ & -0.39 & 0.37 \\
$p$ & 0.15 & 0.17 \\
Right HG & & \\
$r$ & 0.17 & 0.38 \\
$p$ & 0.21 & 0.16 \\
\hline
\end{tabular}

Table 6. Power calculation on the anatomical results for all computed contrasts (Cohen, 1992)

\begin{tabular}{lllll}
\hline Contrast & Left PT & Right PT & Left HG & Right HG \\
\hline PAT/CON & 0.63 & 0.61 & 0.68 & 0.59 \\
PAT/REL & 0.59 & 0.50 & 0.58 & 0.53 \\
CON/REL & 0.51 & 0.50 & 0.61 & 0.55 \\
\hline
\end{tabular}

All values are $r$. PAT, Patients; CON, controls; REL, relatives.

of temporal lobe areas in schizophrenia, which is manifested in gray matter volume as well as functional activation. Furthermore, we found associations between reduced asymmetry in these areas and the severity of positive symptoms, including auditory hallucinations. These findings open up the possibility that reduced $\mathrm{L}>\mathrm{R}$ asymmetry of temporal areas has a genetic contribution. However, replication studies are needed before firm conclusions can be drawn.

Our anatomical results showed a parametric reduction in gray matter volume in the left PT across the groups, independent of age, gender, and years of education. These results conform to previous work of Kasai et al. (2003) and Hirayasu et al. (2000) on 
volumetric changes in schizophrenia patients and, importantly, extend these findings to patients' relatives, in line with volume reductions on a schizophrenia continuum (Lawrie et al., 1999; Fusar-Poli et al., 2007; Broome et al., 2009). The group $\times$ hemisphere interaction for HG was based on a similar left hemispheric volume reduction in the patient and relative groups and thus confirmed such a continuum of structural changes associated with genetic risk. Previous studies had either reported that left HG was larger than the right both in controls and patients (Rojas et al., 1997; Salisbury et al., 2007) or failed to find hemispheric asymmetry (Kulynych et al., 1995; Petty et al., 1995; Barta et al., 1997). However, Salisbury et al. (2007), who used anatomical criteria similar to ours, reported a progressive loss of HG volume in schizophrenia patients (but not in psychotic bipolar patients or controls), which was confined to the left hemisphere. Because our patients were $>15$ years older than theirs, such progressive loss may explain some of the left hemispheric volume reduction in our patients.

The structural imaging literature on temporal lobe asymmetry changes in schizophrenia has been inconsistent, with only half of the published MRI studies reporting changes in patient groups (Chance et al., 2008). A key methodological difference is whether cortical surface or volume was measured. Several of the studies that did not report asymmetry reductions in patients used PT surface (e.g., Kleinschmidt et al., 1994; Kulynych et al., 1995; Leonard et al., 2008), rather than the volume measures used in the present study, although a few studies found reduced or reversed asymmetry with surface measures as well (Barta et al., 1997). Some of the earlier volumetric studies used rather coarse tessellations of the regions of interest (e.g., square grids with several millimeters of spacing) (Frangou et al., 1997), which may have resulted in overestimations of cortical volume and made the method less sensitive. This may also explain the absence of PT volume asymmetry in a large control group in one study (Barta et al., 1997). Studies also differed importantly as to whether they included the part along the ramus posterior of the Sylvian fissure into the PT volume (as we and Kasai et al., 2003) or not (as Shapleske et al., 2001). The latter approach leads to smaller estimates of PT volume, which may reduce the likelihood of finding asymmetry differences in schizophrenia. Another key question is whether to recruit relatives of the study patients, which almost inevitably leads to an older relative group (Frangou et al., 1997), or whether to recruit age-matched relatives who are not necessarily related to the study patients, as in the present study.

A final resolution of the debate around reduced structural asymmetry of the PT and adjacent temporal lobe areas in schizophrenia thus requires a large scale study with a homogeneous and gender- and handedness-matched patient group and a combination of surface and volume measures of the PT and its parts. Alternative diagnostic approaches, for example based on endophenotypes, may be useful for future investigations to further restrict the inherent heterogeneity of symptoms and syndromes within schizophrenia (Gottesman and Gould, 2003; Braff et al., 2007). Another moot case is whether reduced temporal lobe asymmetry, if it exists, is specifically associated with schizophrenia or rather with cognitive impairment and poor coping abilities, as suggested by Leonard et al. (2008). Our findings in relatives would support a specific association with schizophrenia risk, although they do not rule out that altered asymmetry is also an independent risk factor for language or other cognitive impairments. A potential disease-specific association with schizophrenia is also supported by Kasai et al. (2003), who found reduced PT asymmetry and progressive left PT volume loss in schizophrenia patients but not in patients with affective psychosis.

Our functional imaging task elicited robust activity in the superior temporal lobes bilaterally in all groups, consistent with previous work (Hickok et al., 2000). This activation showed a reduced functional $\mathrm{L}>\mathrm{R}$ asymmetry in the patients, which conforms to previous functional imaging studies in schizophrenia with similar results (Sommer et al., 2001; Spaniel et al., 2007; Bleich-Cohen et al., 2009). The superior temporal gyrus (STG) of the dominant hemisphere supports the generation and understanding of individual words (Warren et al., 2005), whereas the nondominant STG has been implicated in the processing of differences in melody, pitch, and sound intensity (Jäncke et al., 1998; Samson et al., 2001). Both of these functions seem to be impaired in schizophrenia, but disruption of semantic processing is more consistently reported (Sommer et al., 2001). Our findings of more marked changes in the left PT, which is the posterior part of the dorsal surface of the STG, would be in keeping with such a distribution of neuropsychological deficits.

The correlation between reduced functional asymmetry and increased severity of positive symptoms conforms to findings of Artiges et al. (2000) and Sommer et al. (2001). Importantly, we also found a similar correlation between reduced anatomical asymmetry and positive symptoms, which suggests that changes in brain organization in schizophrenia strongly contribute to the psychopathological manifestation of the disease (Crow, 1997; Friston, 1998; Stephan et al., 2009). Previous functional neuroimaging and electrophysiological studies have shown that areas in the STG are activated during the experience of auditory hallucinations (Dierks et al., 1999; Ishii et al., 2000; Lennox et al., 2000; van de Ven et al., 2005). Moreover, Kircher et al. (2004) found that altered interaction between regions within the STG and across hemispheres was in part responsible for languagemediated cognitive and psychopathological symptoms in schizophrenia. Anatomical changes may underlie these functional connectivity abnormalities and contribute to the experience of positive symptoms. For example, several studies reported that reductions in left HG volume correlated with hallucinations and delusions (Levitan et al., 1999; Gaser et al., 2004; Sumich et al., 2005).

The concept of hemispheric laterality plays a central role in current neuropsychological and pathophysiological models of schizophrenia (e.g., Løberg et al., 1999; Mitchell and Crow, 2005; Hugdahl et al., 2007; Paul et al., 2007). For example, Angrilli et al. (2009) and Spironelli et al. (2008) proposed a neuropsychological link between reduced language lateralization and the psychopathology of schizophrenia. Moreover, reduced laterality is a target for both twin (Niethammer et al., 2000) and molecular genetics (e.g., Leonard et al., 2006; Francks et al., 2007; Crow et al., 2009) studies and for animal models of schizophrenia (Morice et al., 2005).

The precise neurobiological mechanism that underlies the volume loss in parts of the temporal lobe (Shenton et al., 2001) is still unknown, but a combination of factors preceding the disease, for example a neurodevelopmental abnormality (Rapoport et al., 2005), and factors following the disease, such as medication (Dazzan et al., 2005), has been suggested to contribute to the anatomical aberrations. However, in the latter study, cortical volume reduction mainly resulted from typical neuroleptics, whereas our patients were all treated with atypical antipsychotics, and only four in addition with typical antipsychotic drugs. An analysis of structural asymmetry differences without these four patients showed similar results. We further controlled for sub- 
stantial medication effects by correlation analysis with chlorpromazine equivalents in our patient group. The significant volume loss in the relative group in the left PT compared to controls (but intermediate between patients and controls) could reflect a genetically determined mechanism leading to loss of neurons in schizophrenia (Hulshoff Pol and Kahn, 2008). This hypothesis is supported by findings of genetic studies of families affected with schizophrenia. Many genes implicated in schizophrenia have a direct influence on brain development regulating such processes as neuronal migration, axonal guidance, myelination, neurotransmission, and synaptic plasticity (Owen et al., 2004; Harrison and Weinberger, 2005). Some of these genes have been associated with anatomical brain abnormalities in schizophrenia patients and their first-degree unaffected relatives (Addington et al., 2007; Gruber et al., 2008; van Haren et al., 2008; Winterer et al., 2008; Zinkstok et al., 2008). Many researchers now agree that genetic abnormalities observed in schizophrenia further predispose and sensitize the brain to environmental insults resulting in a life-long dysregulation of brain development and plasticity (Bartzokis, 2002; Pantelis et al., 2005). This may explain why some structural and functional changes are found in relatives, but more pronounced (and potentially progressive) changes are found in the patients.

In conclusion, the reduction of left-right lateralization of temporal lobe structure and function, which was intermediate in the relatives, supports a continuum of schizophrenia-associated anatomical changes. In the patients, the reduced temporal asymmetry is severe enough to contribute to hallucinations and other positive symptoms. Changes in hemispheric asymmetry thus are a promising parameter in pathophysiological and neuropsychological models of schizophrenia, which warrants further investigation both in patients and people at genetic risk.

\section{References}

Addington AM, Gornick MC, Shaw P, Seal J, Gogtay N, Greenstein D, Clasen L, Coffey M, Gochman P, Long R, Rapoport JL (2007) Neuregulin 1 and childhood-onset schizophrenia. Mol Psychiatry 12:195-205.

Aggernaes A (1972) The experienced reality of hallucinations and other psychological phenomena. An empirical analysis. Acta Psychiatr Scand 48:220-238.

American Psychiatric Association (1994) Diagnostic and statistical manual of mental disorders, Ed 4. Washington, DC: APA.

Angrilli A, Spironelli C, Elbert T, Crow TJ, Marano G, Stegagno L (2009) Schizophrenia as failure of left hemispheric dominance for the phonological component of language. PLoS One 4:e4507.

Artiges E, Martinot JL, Verdys M, Attar-Levy D, Mazoyer B, Tzourio N, Giraud MJ, Paillère-Martinot ML (2000) Altered hemispheric functional dominance during word generation in negative schizophrenia. Schizophr Bull 26:709-721.

Barta PE, Pearlson GD, Brill LB 2nd, Royall R, McGilchrist IK, Pulver AE, Powers RE, Casanova MF, Tien AY, Frangou S, Petty RG (1997) Planum temporale asymmetry reversal in schizophrenia: replication and relationship to gray matter abnormalities. Am J Psychiatry 154:661-667.

Bartzokis G (2002) Schizophrenia: breakdown in the well-regulated lifelong process of brain development and maturation. Neuropsychopharmacology 27:672-683.

Bediou B, Asri F, Brunelin J, Krolak-Salmon P, D’Amato T, Saoud M, Tazi I (2007) Emotion recognition and genetic vulnerability to schizophrenia. Br J Psychiatry 191:126-130.

Bleich-Cohen M, Hendler T, Kotler M, Strous RD (2009) Reduced language lateralization in first-episode schizophrenia: an fMRI index of functional asymmetry. Psychiatry Res 171:82-93.

Boos HB, Aleman A, Cahn W, Hulshoff Pol H, Kahn RS (2007) Brain volumes in relatives of patients with schizophrenia: a meta-analysis. Arch Gen Psychiatry 64:297-304.

Boynton GM, Engel SA, Glover GH, Heeger DJ (1996) Linear systems analysis of functional magnetic resonance imaging in human V1. J Neurosci 16:4207-4221.
Braff DL, Freedman R, Schork NJ, Gottesman II (2007) Deconstructing schizophrenia: an overview of the use of endophenotypes in order to understand a complex disorder. Schizophr Bull 33:21-32.

Broome MR, Matthiasson P, Fusar-Poli P, Woolley JB, Johns LC, Tabraham P, Bramon E, Valmaggia L, Williams SC, Brammer MJ, Chitnis X, McGuire PK (2009) Neural correlates of executive function and working memory in the 'at-risk mental state'. Br J Psychiatry 194:25-33.

Cardno AG, Jones LA, Murphy KC, Sanders RD, Asherson P, Owen MJ, McGuffin P (1999) Dimensions of psychosis in affected sibling pairs. Schizophr Bull 25:841-850.

Chance SA, Casanova MF, Switala AE, Crow TJ (2006) Minicolumnar structure in Heschl's gyrus and planum temporale: asymmetries in relation to sex and callosal fiber number. Neuroscience 143:1041-1050.

Chance SA, Casanova MF, Switala AE, Crow TJ (2008) Auditory cortex asymmetry, altered minicolumn spacing and absence of ageing effects in schizophrenia. Brain 131:3178-3192.

Cohen J (1992) A power primer. Psychol Bull 112:155-159.

Crow T (2007) Genetic hypotheses for schizophrenia. Br J Psychiatry 191:180.

Crow TJ (1997) Is schizophrenia the price that Homo sapiens pays for language? Schizophr Res 28:127-141.

Crow TJ, Ball J, Bloom SR, Brown R, Bruton CJ, Colter N, Frith CD, Johnstone EC, Owens DG, Roberts GW (1989) Schizophrenia as an anomaly of development of cerebral asymmetry. A postmortem study and a proposal concerning the genetic basis of the disease. Arch Gen Psychiatry 46:1145-1150.

Crow TJ, Close JP, Dagnall AM, Priddle TH (2009) Where and what is the right shift factor or cerebral dominance gene? A critique of Francks et al. (2007). Laterality 14:3-10.

David AS (1999) Auditory hallucinations: phenomenology, neuropsychology and neuroimaging update. Acta Psychiatr Scand Suppl 395:95-104.

Dazzan P, Morgan KD, Orr K, Hutchinson G, Chitnis X, Suckling J, Fearon P, McGuire PK, Mallett RM, Jones PB, Leff J, Murray RM (2005) Different effects of typical and atypical antipsychotics on grey matter in first episode psychosis: the AESOP study. Neuropsychopharmacology 30:765-774.

Deichmann R, Schwarzbauer C, Turner R (2004) Optimisation of the 3D MDEFT sequence for anatomical brain imaging: technical implications at 1.5 and 3T. Neuroimage 21:757-767.

Dierks T, Linden DEJ, Jandl M, Formisano E, Goebel R, Lanfermann H, Singer W (1999) Activation of Heschl's gyrus during auditory hallucinations. Neuron 22:615-621.

Flor-Henry P (1969) Psychosis and temporal lobe epilepsy. A controlled investigation. Epilepsia 10:363-395.

Francks C, Maegawa S, Laurén J, Abrahams BS, Velayos-Baeza A, Medland SE, Colella S, Groszer M, McAuley EZ, Caffrey TM, Timmusk T, Pruunsild P, Koppel I, Lind PA, Matsumoto-Itaba N, Nicod J, Xiong L, Joober R, Enard W, Krinsky B, et al. (2007) LRRTM1 on chromosome 2p12 is a maternally suppressed gene that is associated paternally with handedness and schizophrenia. Mol Psychiatry 12:1129-1139.

Frangou S, Sharma T, Sigmudsson T, Barta P, Pearlson G, Murray RM (1997) The Maudsley Family Study. 4. Normal planum temporale asymmetry in familial schizophrenia. A volumetric MRI study. Br J Psychiatry 170:328-333.

Friston KJ (1998) The disconnection hypothesis. Schizophr Res 30:115-125.

Frith C (2005) The neural basis of hallucinations and delusions. C R Biol 328:169-175.

Fusar-Poli P, Perez J, Broome M, Borgwardt S, Placentino A, Caverzasi E, Cortesi M, Veggiotti P, Politi P, Barale F, McGuire P (2007) Neurofunctional correlates of vulnerability to psychosis: a systematic review and meta-analysis. Neurosci Biobehav Rev 31:465-484.

Gaab N, Gabrieli JD, Glover GH (2007a) Assessing the influence of scanner background noise on auditory processing. I. An fMRI study comparing three experimental designs with varying degrees of scanner noise. Hum Brain Mapp 28:703-720.

Gaab N, Gabrieli JD, Glover GH (2007b) Assessing the influence of scanner background noise on auditory processing. II. An fMRI study comparing auditory processing in the absence and presence of recorded scanner noise using a sparse design. Hum Brain Mapp 28:721-732.

Galaburda AM, Geschwind N (1981) Anatomical asymmetries in the adult and developing brain and their implications for function. Adv Pediatr 28:271-292.

Gaser C, Nenadic I, Volz HP, Büchel C, Sauer H (2004) Neuroanatomy of 
"hearing voices": a frontotemporal brain structural abnormality associated with auditory hallucinations in schizophrenia. Cereb Cortex 14:91-96.

Genovese CR, Lazar NA, Nichols T (2002) Thresholding of statistical maps in functional neuroimaging using the false discovery rate. Neuroimage 15:870-878.

Gogtay N, Greenstein D, Lenane M, Clasen L, Sharp W, Gochman P, Butler P, Evans A, Rapoport J (2007) Cortical brain development in nonpsychotic siblings of patients with childhood-onset schizophrenia. Arch Gen Psychiatry 64:772-780.

Gottesman II, Gould TD (2003) The endophenotype concept in psychiatry: etymology and strategic intentions. Am J Psychiatry 160:636-645.

Gruber O, Falkai P, Schneider-Axmann T, Schwab SG, Wagner M, Maier W (2008) Neuregulin-1 haplotype HAP(ICE) is associated with lower hippocampal volumes in schizophrenic patients and in non-affected family members. J Psychiatr Res 43:1-6.

Harrison PJ, Weinberger DR (2005) Schizophrenia genes, gene expression, and neuropathology: on the matter of their convergence. Mol Psychiatry 10:40-68.

Hickok G, Poeppel D (2007) The cortical organization of speech processing. Nat Rev Neurosci 8:393-402.

Hickok G, Erhard P, Kassubek J, Helms-Tillery AK, Naeve-Velguth S, Strupp JP, Strick PL, Ugurbil K (2000) A functional magnetic resonance imaging study of the role of left posterior superior temporal gyrus in speech production: implications for the explanation of conduction aphasia. Neurosci Lett 287:156-160.

Hirayasu Y, McCarley RW, Salisbury DF, Tanaka S, Kwon JS, Frumin M, Snyderman D, Yurgelun-Todd D, Kikinis R, Jolesz FA, Shenton ME (2000) Planum temporale and Heschl gyrus volume reduction in schizophrenia: a magnetic resonance imaging study of first-episode patients. Arch Gen Psychiatry 57:692-699.

Honer WG, Bassett AS, Squires-Wheeler E, Falkai P, Smith GN, Lapointe JS, Canero C, Lang DJ (1995) The temporal lobes, reversed asymmetry and the genetics of schizophrenia. Neuroreport 7:221-224.

Hugdahl K, Løberg EM, Specht K, Steen VM, van Wageningen H, Jørgensen HA (2007) Auditory hallucinations in schizophrenia: the role of cognitive, brain structural and genetic disturbances in the left temporal lobe. Front Hum Neurosci 1:6.

Hulshoff Pol HE, Kahn RS (2008) What happens after the first episode? A review of progressive brain changes in chronically ill patients with schizophrenia. Schizophr Bull 34:354-366.

Hutsler J, Galuske RA (2003) Hemispheric asymmetries in cerebral cortical networks. Trends Neurosci 26:429-435.

Ishii R, Shinosaki K, Ikejiri Y, Ukai S, Yamashita K, Iwase M, MizunoMatsumoto Y, Inouye T, Yoshimine T, Hirabuki N, Robinson SE, Takeda M (2000) Theta rhythm increases in left superior temporal cortex during auditory hallucinations in schizophrenia: a case report. Neuroreport 11:3283-3287.

Jäncke L, Shah NJ, Posse S, Grosse-Ryuken M, Müller-Gärtner HW (1998) Intensity coding of auditory stimuli: an fMRI study. Neuropsychologia 36:875-883.

Kasai K, Shenton ME, Salisbury DF, Hirayasu Y, Onitsuka T, Spencer MH, Yurgelun-Todd DA, Kikinis R, Jolesz FA, McCarley RW (2003) Progressive decrease of left Heschl gyrus and planum temporale gray matter volume in first-episode schizophrenia. Arch Gen Psychiatry 60:766-775.

Kawasaki Y, Suzuki M, Takahashi T, Nohara S, McGuire PK, Seto H, Kurachi M (2008) Anomalous cerebral asymmetry in patients with schizophrenia demonstrated by voxel-based morphometry. Biol Psychiatry 63:793-800.

Kay SR, Fiszbein A, Opler LA (1987) The Positive and Negative Symptom Scale (PANSS) for schizophrenia. Schizophr Bull 13:261-276.

Keshavan MS, Dick E, Mankowski I, Harenski K, Montrose DM, Diwadkar V, DeBellis M (2002) Decreased left amygdala and hippocampal volumes in young offspring at risk for schizophrenia. Schizophr Res 58:173-183.

Kircher TT, Rapp A, Grodd W, Buchkremer G, Weiskopf N, Lutzenberger W, Ackermann H, Mathiak K (2004) Mismatch negativity responses in schizophrenia: a combined fMRI and whole-head MEG study. Am J Psychiatry 161:294-304.

Kleinschmidt A, Falkai P, Huang Y, Schneider T, Fürst G, Steinmetz H (1994) In vivo morphometry of planum temporale asymmetry in firstepisode schizophrenia. Schizophr Res 12:9-18.

Kulynych JJ, Vladar K, Fantie BD, Jones DW, Weinberger DR (1995) Nor- mal asymmetry of the planum temporale in patients with schizophrenia. Three-dimensional cortical morphometry with MRI. Br J Psychiatry 166:742-749.

Kwon JS, McCarley RW, Hirayasu Y, Anderson JE, Fischer IA, Kikinis R, Jolesz FA, Shenton ME (1999) Left planum temporale volume reduction in schizophrenia. Arch Gen Psychiatry 56:142-148.

Lawrie SM, Whalley H, Kestelman JN, Abukmeil SS, Byrne M, Hodges A, Rimmington JE, Best JJ, Owens DG, Johnstone EC (1999) Magnetic resonance imaging of brain in people at high risk of developing schizophrenia. Lancet 353:30-33.

Lawrie SM, McIntosh AM, Hall J, Owens DG, Johnstone EC (2008) Brain structure and function changes during the development of schizophrenia: the evidence from studies of subjects at increased genetic risk. Schizophr Bull 34:330-340.

Lennox BR, Park SB, Medley I, Morris PG, Jones PB (2000) The functional anatomy of auditory hallucinations in schizophrenia. Psychiatry Res 100:13-20.

Leonard CM, Eckert MA, Kuldau JM (2006) Exploiting human anatomical variability as a link between genome and cognome. Genes Brain Behav 5 [Suppl 1]:64-77.

Leonard CM, Kuldau JM, Maron L, Ricciuti N, Mahoney B, Bengtson M, DeBose C (2008) Identical neural risk factors predict cognitive deficit in dyslexia and schizophrenia. Neuropsychology 22:147-158.

Levitan C, Ward PB, Catts SV (1999) Superior temporal gyral volumes and laterality correlates of auditory hallucinations in schizophrenia. Biol Psychiatry 46:955-962.

Li X, Branch CA, Ardekani BA, Bertisch H, Hicks C, DeLisi LE (2007) fMRI study of language activation in schizophrenia, schizoaffective disorder and in individuals genetically at high risk. Schizophr Res 96:14-24.

Løberg EM, Hugdahl K, Green MF (1999) Hemispheric asymmetry in schizophrenia: a "dual deficits" model. Biol Psychiatry 45:76-81.

McGuffin P, Owen MJ, Farmer AE (1995) Genetic basis of schizophrenia. Lancet 346:678-682.

Mitchell RLC, Crow TJ (2005) Right hemisphere language functions and schizophrenia: the forgotten hemisphere? Brain 128:963-978.

Morice E, Denis C, Macario A, Giros B, Nosten-Bertrand M (2005) Constitutive hyperdopaminergia is functionally associated with reduced behavioral lateralization. Neuropsychopharmacology 30:575-581.

Morosan P, Rademacher J, Schleicher A, Amunts K, Schormann T, Zilles K (2001) Human primary auditory cortex: cytoarchitectonic subdivisions and mapping into a spatial reference system. Neuroimage 13:684-701.

Morrison AP, Wells A, Nothard S (2002) Cognitive and emotional predictors of predisposition to hallucinations in non-patients. Br J Clin Psychol 41:259-270.

Niethammer R, Weisbrod M, Schiesser S, Grothe J, Maier S, Peter U, Kaufmann C, Schröder J, Sauer H (2000) Genetic influence on laterality in schizophrenia? A twin study of neurological soft signs. Am J Psychiatry 157:272-274.

Nishida T, Kudo T, Inoue Y, Nakamura F, Yoshimura M, Matsuda K, Yagi K, Fujiwara T (2006) Postictal mania versus postictal psychosis: differences in clinical features, epileptogenic zone, and brain functional changes during postictal period. Epilepsia 47:2104-2114.

Oldfield RC (1971) The assessment and analysis of handedness: the Edinburgh inventory. Neuropsychologia 9:97-113.

Owen MJ, Williams NM, O’Donovan MC (2004) The molecular genetics of schizophrenia: new findings promise new insights. Mol Psychiatry 9:14-27.

Pantelis C, Yücel M, Wood SJ, Velakoulis D, Sun D, Berger G, Stuart GW, Yung A, Phillips L, McGorry PD (2005) Structural brain imaging evidence for multiple pathological processes at different stages of brain development in schizophrenia. Schizophr Bull 31:672-696.

Paul LK, Brown WS, Adolphs R, Tyszka JM, Richards LJ, Mukherjee P, Sherr EH (2007) Agenesis of the corpus callosum: genetic, developmental and functional aspects of connectivity. Nat Rev Neurosci 8:287-299.

Penhune VB, Zatorre RJ, MacDonald JD, Evans AC (1996) Interhemispheric anatomical differences in human primary auditory cortex: probabilistic mapping and volume measurement from magnetic resonance scans. Cereb Cortex 6:661-672.

Petty RG, Barta PE, Pearlson GD, McGilchrist IK, Lewis RW, Tien AY, Pulver A, Vaughn DD, Casanova MF, Powers RE (1995) Reversal of asymmetry of the planum temporale in schizophrenia. Am J Psychiatry 152:715-721. Prvulovic D, Hubl D, Sack AT, Melillo L, Maurer K, Frölich L, Lanfermann H, 
Zanella FE, Goebel R, Linden DE, Dierks T (2002) Functional imaging of visuospatial processing in Alzheimer's disease. Neuroimage 17:14031414.

Rademacher J, Morosan P, Schormann T, Schleicher A, Werner C, Freund HJ, Zilles K (2001) Probabilistic mapping and volume measurement of human primary auditory cortex. Neuroimage 13:669-683.

Rapoport JL, Addington A, Frangou S (2005) The neurodevelopmental model of schizophrenia: what can very early onset cases tell us? Curr Psychiatry Rep 7:81-82.

Razafimandimby A, Maïza O, Hervé PY, Lecardeur L, Delamillieure P, Brazo P, Mazoyer B, Tzourio-Mazoyer N, Dollfus S (2007) Stability of functional language lateralization over time in schizophrenia patients. Schizophr Res 94:197-206.

Rojas DC, Teale P, Sheeder J, Simon J, Reite M (1997) Sex-specific expression of Heschl's gyrus functional and structural abnormalities in paranoid schizophrenia. Am J Psychiatry 154:1655-1662.

Rotarska-Jagiela A, Schönmeyer R, Oertel V, Haenschel C, Vogeley K, Linden DEJ (2008) The corpus callosum in schizophrenia-volume and connectivity changes affect specific regions. Neuroimage 39:1522-1532.

Salisbury DF, Kuroki N, Kasai K, Shenton ME, McCarley RW (2007) Progressive and interrelated functional and structural evidence of post-onset brain reduction in schizophrenia. Arch Gen Psychiatry 64:521-529.

Samson Y, Belin P, Thivard L, Boddaert N, Crozier S, Zilbovicius M (2001) Auditory perception and language: functional imaging of speech sensitive auditory cortex. Rev Neurol (Paris) 157:837-846.

Schönmeyer R, Prvulovic D, Rotarska-Jagiela A, Haenschel C, Linden DE (2006) Automated segmentation of lateral ventricles from human and primate magnetic resonance images using cognition network technology. Magn Reson Imaging 24:1377-1387.

Shapleske J, Rossell SL, Simmons A, David AS, Woodruff PW (2001) Are auditory hallucinations the consequence of abnormal cerebral lateralization? A morphometric MRI study of the sylvian fissure and planum temporale. Biol Psychiatry 49:685-693.

Shenton ME, Dickey CC, Frumin M, McCarley RW (2001) A review of MRI findings in schizophrenia. Schizophr Res 49:1-52.

Sommer IE, Ramsey NF, Kahn RS (2001) Language lateralization in schizophrenia, an fMRI study. Schizophr Res 52:57-67.

Sommer IE, Ramsey NF, Mandl RC, van Oel CJ, Kahn RS (2004) Language activation in monozygotic twins discordant for schizophrenia. Br J Psychiatry 184:128-135.

Spaniel F, Tintera J, Hajek T, Horacek J, Dezortova M, Hajek M, Dockery C, Kozeny J, Höschl C (2007) Language lateralization in monozygotic twins discordant and concordant for schizophrenia. A functional MRI pilot study. Eur Psychiatry 22:319-322.

Spironelli C, Angrilli A, Stegagno L (2008) Failure of language lateralization in schizophrenia patients: an ERP-study on early linguistic components. J Psychiatry Neurosci 33:235-243.

Stephan KE, Friston KJ, Frith CD (2009) Dysconnection in schizophrenia: from abnormal synaptic plasticity to failures of self-monitoring. Schizophr Bull 35:509-527.

Stephane M, Barton S, Boutros NN (2001) Auditory verbal hallucinations and dysfunction of the neural substrates of speech. Schizophr Res 50:61-78.

Sumich A, Chitnis XA, Fannon DG, O'Ceallaigh S, Doku VC, Faldrowicz A, Sharma T (2005) Unreality symptoms and volumetric measures of Heschl's gyrus and planum temporal in first-episode psychosis. Biol Psychiatry 57:947-950.

Takahashi T, Suzuki M, Zhou SY, Tanino R, Hagino H, Niu L, Kawasaki Y, Seto H, Kurachi M (2006) Temporal lobe gray matter in schizophrenia spectrum: a volumetric MRI study of the fusiform gyrus, parahippocampal gyrus, and middle and inferior temporal gyri. Schizophr Res $87: 116-126$.

Talairach J, Tournoux P (1988) Co-planar stereotaxic atlas of the human brain. New York: Thieme Medical.

van de Ven VG, Formisano E, Prvulovic D, Roeder CH, Linden DE (2004) Functional connectivity as revealed by spatial independent component analysis of fMRI measurements during rest. Hum Brain Mapp 22:165-178.

van de Ven VG, Formisano E, Röder CH, Prvulovic D, Bittner RA, Dietz MG, Hubl D, Dierks T, Federspiel A, Esposito F, Di Salle F, Jansma B, Goebel R, Linden DE (2005) The spatiotemporal pattern of auditory cortical responses during verbal hallucinations. Neuroimage 27: $644-655$

van Haren NE, Bakker SC, Kahn RS (2008) Genes and structural brain imaging in schizophrenia. Curr Opin Psychiatry 21:161-167.

Warren JD, Jennings AR, Griffiths TD (2005) Analysis of the spectral envelope of sounds by the human brain. Neuroimage 24:1052-1057.

Whalley HC, Harris JC, Lawrie SM (2007) The neurobiological underpinnings of risk and conversion in relatives of patients with schizophrenia. Int Rev Psychiatry 19:383-397.

Whyte MC, Whalley HC, Simonotto E, Flett S, Shillcock R, Marshall I, Goddard NH, Johnstone EC, Lawrie SM (2006) Event-related fMRI of word classification and successful word recognition in subjects at genetically enhanced risk of schizophrenia. Psychol Med 36:1427-1439.

Winterer G, Konrad A, Vucurevic G, Musso F, Stoeter P, Dahmen N (2008) Association of $5^{\prime}$ end neuregulin-1 (NRG1) gene variation with subcortical medial frontal microstructure in humans. Neuroimage 40:712-718.

Wittchen H-U, Wunderlich U, Gruschwitz S, Zaudig M (1996) Strukturiertes Klinisches Interview für DSM-IV (SKID). Göttingen: Beltz-Test.

Woods SW (2003) Chlorpromazine equivalent doses for the newer atypical antipsychotics. J Clin Psychiatry 64:663-667.

Zatorre RJ, Belin P, Penhune VB (2002) Structure and function of auditory cortex: music and speech. Trends Cogn Sci 6:37-46.

Zinkstok J, Schmitz N, van Amelsvoort T, Moeton M, Baas F, Linszen D (2008) Genetic variation in COMT and PRODH is associated with brain anatomy in patients with schizophrenia. Genes Brain Behav 7:61-69. 